\title{
RHEUMATIC FEVER AND THE HAEMOLYTIC STREPTOCOCCUS
}

\author{
By George R. Fearnley, M.D., M.R.C.P. \\ Lecturer in Medicine, the Postgraduate Medical School of London
}

Evidence of the association of rheumatic fever with antecedent streptococcal infection is impressive. The exact nature of the relationship, however, is still a matter of speculation, lighted in places by suggestive, but not conclusive experimental work.

Before considering the evidence relating haemolytic streptococcal infection with rheumatic fever, the theories which have been held as to the immediate cause of the disease must be mentioned. Various rôles have been ascribed to streptococci, including those of direct invader, toxin producer and allergen. Virus infection, potentiated or not by streptococcal infection, has also been suggested.

\section{Direct Infection}

In the early days of bacteriology many different organisms were cultured from the blood, joints, pericardial exudates and heart valves of patients who had rheumatic fever (Mantle, 1887; Thiroloix, 1896; Singer, 1895). The work of Poynton and Paine (1900, 1913) focused attention on the streptococcus, and since then papers too numerous to list reporting the culture of streptococci in this disease have appeared. Cecil and co-workers (1929) cultured an attenuated beta haemolytic streptococcus in more than half their patients with rheumatic fever. Green (1942) was able to culture Str. pyogenes from the heart valves of rheumatic fever patients at post-mortem, and where the organisms had been isolated from the throat during life he found the same Griffith type in the heart and throat. However, Dawson et al. (193I), using Cecil's method, were able to find streptococci in sterile agar tubes. Epstein and Kugel (1929) grew streptococci from 40 per cent. of normal heart valves. Menkin (193I) has shown that organisms may localize secondarily at any inflamed site. Apart from the fact that the lesions of rheumatic fever in no way resemble those produced by direct streptococcal infection, the weight of experimental evidence is against it. Green's work is perhaps more difficult to disregard than that of others. Contamination of culture media and post-mortem localization of organisms probably explain most of the positive results obtained by other workers, but post-mortem localization may have occurred in Green's cases.

\section{Virus Infection}

Schlesinger (1935) centrifuged pericardial and pleural fluids from dead rheumatic patients and obtained virus-like particles which were agglutinated by sera from other rheumatic patients and not by sera from normals. He was unable to reproduce the disease by injection of suspensions of these particles into animals. Sera from patients with rheumatoid arthritis show an entirely nonspecific agglutination of particles, including streptococci, a phenomenon which has led to misleading conclusions in the past, and it may be that rheumatic fever sera on occasions will behave similarly. Efforts to obtain pleuro-pneumonia-like organisms (which cause an arthritis in rodents not unlike rheumatoid arthritis) from rheumatic fever patients by Angevine (1940) were unsuccessful. Macneal (1945, 1946) was able to produce lesions resembling those of acute rheumatism by injecting material from severely ill patients into rabbits. Copeman (1944) induced fever, rheumatic pains and elevated sedimentation rates in volunteers by injecting them with blood from a patient suffering from rheumatic fever. He did not succeed, however, in giving his volunteers unequivocal rheumatic fever. That rheumatic fever is a virus infection is possible, but the contention requires more evidence than has been so far forthcoming to make it tenable.

\section{Antecedent Streptococcal Infection}

Following the work of Coburn (1931), many investigators have shown that rheumatic fever in most, if not in all instances, is preceded by an upper respiratory infection with Group A (Lancefield) haemolytic streptococci one to three weeks before the onset of the disease. Such infections 
may be subclinical; it is common experience that a history of preceding sore throat is not always obtained from patients. However, most workers who have been able to study patients before attacks have isolated haemolytic streptococci from their throats (Coburn and Pauli, 1932a, 1932b; Holbrook, 1944; Swift, 1947).

In the United States Forces during World War II, a close relationship between Group A haemolytic streptococcal infections in epidemic form and subsequent rheumatic fever was noted (Coburn, 1944; Feasby, 1944; Holbrook and van Ravenswaay, 1944). The carrier rate for Group A streptococci in healthy troops was shown by van Ravenswa $y$ to parallel the incidence of rheumatic fever. Rantz et al. (1947a) studied the sequelae of strept coccal sore throat in a large number of persons. About 20 per cent. had late complications, such as arthritis, carditis, fever, skin lesions and other manifestations, which they suggest terming the ' post-streptococcic state.'

Another indirect line of evidence linking rheumatic fever with streptococcal infection is the success achieved in diminishing both streptococcal infection and rheumatic fever recurrences, in children, by small daily doses of sulphonamides over long periods (Baldwin, 1947; Barclay, 1945; Dodge, 1944; Kuttner, 1945). Diminution of the number of cases of rheumatic fever in the United States Army Camps, where the incidence of streptococcal infection and rheumatic fever was high, was obtained by similar prophylaxis on a large scale. Penicillin has also been used successfully (Maliner, 1947; Massell, 1948) and is at present under extensive trial.

Massell (1948) in a study of penicillin prophylaxis obtained evidence that large doses of penicillin, given early during tonsillitis, would prevent subsequent rheumatic fever. Of great interest is the recent report of Denny et al. (1950), who studied the effects of large doses of penicillin on members of the U.S. Forces stationed at Fort Warren, Wyoming, where the incidence of streptococcal infection and rheumatic fever is high. A total of r,634 men with acute streptococcal tonsillitis was studied. Only those with exudate on the tonsils and pharyngeal wall were included; 798 patients were given 300,000 units of procaine penicillin (in peanut oil with 2 per cent. aluminium monostearate), and 600,000 units 96 hours later. 804 patients served as controls. In the treated group only two cases of rheumatic fever occurred; in the control group the disease developed in 17 . Penicillin given in this way also suppressed the antistreptolysin $\mathrm{O}$ response and eradicated streptococci in many cases.

If this work can be confirmed it is the strongest evidence yet obtained of a causal relationship between streptococcal sore throat and rheumatic fever. While these results point to the importance of treating patients with acute tonsillitis early with large doses of penicillin, the incidence of rheumatic fever is unlikely to be reduced thereby, since the mild sore throat is just as, or even more, likely than the florid tonsillitis to be followed by rheumatic fever. The organization at Fort Warren was geared to obtain cases within a short time of the onset of symptoms, and in general such conditions cannot be obtained in civilian life. However, they can be organized in schools and institutions for the care of rheumatic children, and in the case of the child at home who has had previous attacks of acute rheumatism, the parents can be instructed on the importance of medical advice if their child develops a sore throat.

Finally, the immunological evidence which may have a bearing on the development of rheumatic fever must be considered. Coburn and Pauli (1932c, 1935, I939) investigated antibody production against the streptococcus in streptococcal infections and in acute rheumatism. Whereas antistreptolysin $\mathrm{O}$ titres were low or negative in controls, they were raised both in patients with streptococcal sore throat and rheumatic fever. In rheumatic fever the rise in antistreptolysin paralleled the severity of the attack and was pros longed. Coburn believed that all attacks or reכ currences of rheumatic fever are accompanied by a rise in antistreptolysin $O$ (1945). While other workers' results agree in the main with his, there have been many reports of rheumatic attacks without a rise in antistreptolysin $\mathrm{O}$. Wilson (1935) found no rise in two thirds of attacks of rheumatic fever not preceded by clinical infection, and was unable to correlate in general rheumatic attacks with the antistreptolysin titre. Her failure to do so may have been due to the high basal value for antistreptolysin she used. It is quite possible that some strains of Group A streptococci do not produce streptolysin $\mathrm{O}$, in which case antistreptolysin titres would not be altered if such strains were involved.

Precipitin and antifibrinolysin (antistreptokinase) titres also are usually increased during rheumatic fever. Antistreptolysin $\mathrm{S}$ appears to 0 decrease during an attack, an unique phenomenon which merits further study.

In summary, the evidence adduced from these different lines of inquiry points to participation of $Q$ Group A streptococci in the development of $\bar{\varnothing}$ rheumatic fever. How the organism exerts its $\stackrel{?}{+}$ effects is another matter. Here we leave the light ${ }^{\circ}$ of experience for a darkness cross-lit by experiment and hypothesis. 


\section{Possible Mechanisms}

The relation of streptococcal infection to rheumatic fever is not a direct one of cause and effect. Two theories have been advanced to account for the intervening factors. The first, the allergic theory, is a rational hypothesis which satisfies the situation; the second, the theory that rheumatic fever is caused by a streptococcal toxin, has the objection that rheumatic fever develops not at a time when toxin production may be presumed to be at its highest, but subsequently. The allergic theory is therefore the more attractive explanation of the known facts. Its appeal, however, should not be allowed to rule out the possible responsibility of a streptococcal toxin.

Another view would include rheumatic fever among Selye's 'diseases of adaptation.' The capacity of the individual to adapt to stresses of various kinds according to this theory would seem dependent on his state of nutrition and heredity (Selye, 1950). Selye's terms ' alarm reaction,' 'stage of resistance' and 'stage of exhaustion' are the banners of a vitalistic approach to understanding the organism as a constant struggle between adaptation and stress. It is not within the scope of this article to review Selye's work, but it must be said that the thesis of disordered adaptation as a perversion of the normal pituitaryadrenal response to stress, with the production not of gluco-corticoids but of an excess of mineralo-corticoids, has not found general acceptance. Be this as it may, the 'disordered adaptation' theory is not at variance with the view that the rheumatic fever patient is an individual who has reacted abnormally to haemolytic streptococcal infection. Whether rheumatic fever is due to a streptococcal toxin, a disorder of immune response, or a disorder of adaptation to such infection, it is evident that those who develop rheumatic fever after such infection differ in some way from those who do not. It has been amply demonstrated that when the same streptococcus infects a group of individuals rheumatic fever develops only in a minority. The tendency of the rheumatic patient to develop further attacks of the disease on further exposure to infection is wrell known.

\section{Heredity}

Newsholme (1895) showed from extensive data that rheumatic fever had a predilection for certain families. He interpreted this as evidence that the disease is epidemic. His findings can equally well be ascribed to an hereditary factor in its genesis, and this choice of interpretation applies to most of the information collected subsequently. May Wilson (1944) believes that susceptibility to rheumatic fever is transmitted as a single, autosomal, recessive gene. Not all persons susceptible con- $\frac{2}{3}$ tract the disease, which she believes to depend on $\stackrel{\mathbb{D}}{\stackrel{2}{2}}$ penetrance. At puberty penetrance is known to $c$ decrease markedly. Griffith (1948), however, has $\vec{F}$ found that if persons from rheumatic families are $\stackrel{0}{+}$ separated from their families they have no more rheumatic attacks than those from non-rheumatic backgrounds. An extraordinary family in which 24 of 53 descendants of one rheumatic individual had rheumatic heart disease was described by Pickles (1943).

In spite of the valuable studies of Wilson and others, therefore, when a patient dies from rheumatic heart disease we still do not know whether he was doomed by heredity or by environment.

\section{Diet}

The once widely held hypothesis that dietary deficiency of ascorbic acid is a conditioning factor in rheumatic fever followed Rinehart's observation of fibrinoid changes in the periarticular tissues of scorbutic guinea pigs infected with streptococci. The changes resembled those described by Klinge in rheumatic fever. Plasma ascorbic acid levels were found to be significantly lowered in patients with rheumatic fever compared witho controls and patients with other diseases. Rinee hart subsequently abandoned his hypothesis (1943), considering the ascorbic acid changes to be an effect and not a cause of the disease. The recent papers of Long et al. (r950a, b) concerning the possible mediation of cortisone in the peripheral metabolism of ascorbic acid should be consulted. It would be premature at this time to consider the effects of adrenal cortical hormones on anaphylaxis, allergy and the cellular changes of inflammation in an attempt to throw more light on rheumatic fever. The evidence is still in many ways conflicting, but it is probable that a great deal of information about the rheumatic diseases will accrue from the experimental use of $\mathrm{ACTH}$ and cortisone.

Coburn (1943), arguing that patients with high blood lipids are refractory to rheumatic fever, studied under-privileged children in New York City. Taking three groups, 30 in each, he gave one its customary diet, to the second the same diet plus large doses of powdered egg, and to the third a first-class diet. The incidence of rheumatic fever in the groups was 38 per cent; 6.7 per cent. and 5 per cent. respectively. To have significance the study would have to be repeated on a much larger scale; the writer is not aware of further work on these lines. Finally, it must be remembered when considering dietary deficiency as a factor that rheumatic fever is commonest not among the very poor, but among the less well-to-do working class. 


\section{Toxins}

Group A haemolytic streptococci produce a number of toxins, some of which are enzymes. When it became unlikely that rheumatic fever is due to systemic invasion by the organisms themselves, the focus of interest turned to streptococcal toxins as a possible cause. The known toxins of the haemolytic streptococcus include the erythrogenic toxin, which gives the rash of scarlet fever and is produced only by. certain strains; leucocidin; streptolysin $\mathrm{O}$ and streptolysin $\mathrm{S}$, the haemolytic toxins; streptokinase (Christenson, 1945), an enzyme which converts the pro-enzyme plasminogen to plasmin (serum protease) which in turn lyses fibrinogen and fibrin; streptodornase, an enzyme which depolymerizes desoxyribosenucleic acid; and hyaluronidase, an enzyme which has especially interested workers in the rheumatic field.

If streptokinase or trypsin is injected under the skin of rabbits inflammatory nodules form, presumably a reaction to proteolysis, but they do not resemble the nodules of rheumatic fever. Haemolysis is a feature of streptococcal septicaemia, but not of rheumatic fever; the antistreptolysin $O$ titre of the latter disease is not an indication that streptolysin is responsible for rheumatic lesions.

\section{Hyaluronidase}

Filling the interstices of mesodermal tissues and acting as 'cement' between cellular and noncellular structures is the ' ground substance.' This long-neglected component of connective tissue has been subjected to much interest and work in recent years, and is being studied extensively by histological, histochemical and biochemical methods. For information about ground substance and its pathology the reader is referred to the papers of Klinge, Meyer and Klemperer, and to the symposium on connective tissue (Ragan, 1950) published by the Macy Foundation. Ground substance (substances) consists of various polysaccharides attached to protein; one of these is hyaluronic acid, a polymer of glucuronic acid and glucosamine in equimolar proportions. The particular polysaccharide varies with different tissues. Hyaluronic acid has been isolated from skin, synovial fluid, vitreous humour and umbilical cord, and is thought to be an important component of the ground substance of connective tissue (Meyer, 1947, 1948). It has been extensively studied by Meyer (1938). The evidence that hyaluronate is a constituent of ground substances is somewhat indirect. Joint cavities may be considered as clefts in connective tissue and the synovial fluid as ground substance. Synovial fluid contains hyaluronate which gives it a high viscosity. In rheumatoid arthritis considerable depolymerization of the polysaccharide occurs with resultant lowering of viscosity. Other evidences are the spreading activity of hyaluronidase and the presence of material throughout connective tissues, which, like hyaluronate, stains metachromatically.

Hyaluronidases, enzymes or mixtures of enzymes, can be obtained from testicular tissue and from various organisms, especially streptococci. The attractive theory that the fibrinoid lesions of rheumatic fever are due to depolymerization of ground substance by streptococcal hyaluronidase naturally presented. If hyaluronidase together with a dye such as haemoglobin is injected into the skin, rapid spreading of the dye, compared with control injections of the dye alone, occurs. Guerra (1946) claimed administration of salicylates prevented this spreading action of hyaluronidase in the skin. It thus appeared that salicylates antagonized hyaluronidase in vivo. However, although most Group A streptococci under appropriate conditions will produce hyaluronidase it is the unencapsulated organisms which do so (the capsule itself consists of hyaluronic acid), whereas the streptococci of the infections preceding rheumatic exacerbations are encapsulated and virulent (Pilot, 1944). Group C streptococci, which are not im plicated in rheumatic fever, also produce the enzyme. Ragan and Harris, among others, were unable to confirm Guerra's observation of hyaluronidase inhibition in vivo by salicylates. The fact that hyaluronidase inhibitor is increased in rheumatic fever is probably not of significance by itself, being merely another example of antibody production to streptococcal products.

Enthusiasm for hyaluronidase and hyaluronic acid for a time drew attention away from other connective tissue components such as chondroitin sulphate. It has been somewhat glibly implied that fibrinoid, the material which stains like fibrin in the lesions of the collagen diseases, is depolymerized hyaluronate. In fact, the nature of fibrinoid is still obscure and subject to considerable debate among workers in the field (Ragan, 1950). It can be said that so far observation and experimental work have not yielded conclusive evidence of hyaluronidase being an enzymic malefactor in rheumatic fever.

\section{The Allergic Factor}

The likelihood that rheumatic fever represents an abnormal reaction to streptococcal infection and the anomalous behaviour of antibody response during the disease have suggested that rheumatic fever may result from allergy to streptococcal products. Suggestive evidence of lupus erythematosus and periarteritis nodosa being allergic diseases has been obtained, sulphonamides being 
one of the allergens held responsible for the latter. Serum sickness is an allergic condition accompanied by acutely inflamed joints. A word of caution must be pronounced, against the facile concept of a ' spectrum of collagenoses,' including lupus, periarteritis, rheumatoid arthritis and rheumatic fever, implying that these diseases are variants on a theme. While there is evidence that transition between these conditions may occur, and while close clinical similarities may sometimes exist, it is unwise at present to group these diseases as if they had a similar aetiology. This may prove to be so, but we are not justified in assuming a closer relationship than would be manifested by tissues whose reactive patterns are limited.

In many ways rheumatic fever is reminiscent of an allergic condition. It is sudden in onset, has a marked tendency to recur, and appears to be related to a precipitating illness; development of immunity is absent. Klinge (1933) considered that formation of fibrinoid (often incorrectly called fibrinoid degeneration of collagen, but there is no certainty that collagen itself gives rise to fibrinoid) is characteristic of allergic-hyperergic inflammation. Rantz (1945), after considering the evidence thoroughly, is convinced that rheumatic fever is invariably induced by infection with haemolytic streptococci and therefore represents hypersensitivity to some product common to different streptococcal types.

A higher percentage of positive reactors to skin tests with streptococcal products has been found among active than among quiescent rheumatic cases and normals. Short (1934) has pointed out, however, the non-specific character of such reactions and Jones and Mote (1948) found that rheumatic fever patients react to plain rabbit serum. This would suggest that rheumatic patients are in a state of general hypersensitivity, but the non-specificity of this sensitivity should not be taken as an argument against the haemolytic streptococcus as a causative agent.

Murphy and Swift (1949) using rabbits were able to produce a rheumatic fever-like illness by by injecting a small dose of streptococci subcutaneously, and following this a few weeks later with a small dose of a different type of organism. With repeated innoculations, lesions which closely resembled human lesions were found in the heart valves and myocardium. The pathogenicity of Group A streptococci is closely correlated with the presence of M protein. Rothbard (1948) has shown that a high degree of immunity in mice to Group A streptococcal infection is afforded by type-specific antiserum, and that type-specific immunity develops after infection with a particular type. This, in conjunction with Swift's work, suggests that rheumatic fever recurrences may be the result of infections with further streptococcal types to which the individual is not immune.

Another hypothesis relating rheumatic fever to allergy has recently been propounded (Kerr, I948). This hypothesis, first developed for glomerulonephritis, suggests that rheumatic patients form antibodies against antigens which consist of their own denatured proteins combined as haptens with some streptococcal material. There are similarities between rheumatic fever and glomerulonephritis in their streptococcal relationships, and both give skin reactions to streptococcal filtrates and to plain rabbit serum. Masugi was able to produce glomerulonephritis in animals with 'nephrotoxic' sera, i.e. sera prepared by immunizing the animal with extracts of its own kidneys. A number of workers with conflicting results have investigated the auto-antibody hypothesis in the production of lesions hoped to resemble those of acute rheumatism. The hypothesis is at present no more than an interesting possibility.

Rich and Gregory (1946) by repeated injection of horse serum or egg albumin into rabbits were able to produce a generalized condition like periarteritis nodosa. The cardiac lesions resembled those of rheumatic fever and the renal lesions suggested glomerulonephritis. Rich has collected evidence to show the frequent occurrence of periarteritis nodosa in serum sickness and during sulphonamide therapy.

It cannot be logically argued, however, that the production of such lesions by various means indicates that rheumatic fever is an allergic or anaphylactic disease. In the first place nobody has succeeded in producing unequivocal rheumatic lesions in animals. Periarteritis nodosa is not rheumatic fever, and the concept mentioned before that periarteritis, rheumatic fever, etc., are different manifestations of a common process is no more then a hypothesis, so far not supported by very much experimental or observational evidence. It must not be forgotten that similar histological pictures may be produced by different agents, and that the reaction pattern of a particular tissue may be limited.

\section{BIBLIOGRAPHY}

ANGEVINE, D. M., et al. (1940), Ұ.A.M.A., 115, 2112. BALDWIN, J. S. (1947), f. Pediat., 30, 284. BARCLAY, P. E., and KING-LEWIS, F. L. (1945), Lancet, ii, 75 r. CECIL, R. L., et al. (1929), Э. exp. Med., 50, 617. CHRISTENSON, L. R. (1945), \%. Gen. Physiol., 28, 363. COBURN, A. F. (1931) ' The Factor of Infection in the Rheumatic State,' Baltimore, Williams and Williams.
COBURN, A. F. (1944), Y.A.M.A., 124, 88.

COBURN, A. F. (1945), Am. f. Dis. Child., 70, 339.

COBURN, A. F., and MOORE, L. V. (1943), Ibid., 65, 744. COBURN, A. F., and PAULI, R. H. (1932a), f. Exper. Med., 56, 609.

COBURN, A. F., and PAULI, R. H. (1932b), Ibid., 56, 633 . COBURN, A. F., and PAULI, R. H. (1932C), Ibid., 56, 651. 
COBURN, A. F., and PAULI, R. H. (1935), Ibid., 62, 129. COBURN, A. F., and PAULI, R. H. (1939), ₹. Clin. Invest., 18, 141. COPEMAN, W. S. C. (1944), Ann. Rhermat. Dis., 437.

DAWSON, M. H., et al. (1931), Proc. Soc. Exp. Biol. Med., 28, 419. DENNY, F. W., et al. (1950), F.A.M.A., 143, 15 x.

DODGE, K. G., BALDWIN, J. S., and WEBER, M. W. (1944), 7. Pediat, 24,483 .

EPSTEIN, E. Z., and KUGEL, M. A. (1929), $\mathcal{F}$. Inf. Dis., 44327.

FEASBY, W. R. (1944), War. Med., 5, 216.

GREEN, C. A. (1942), Ann. Rheumat. Dis., 3, 4.

GRIFFITH, G. C., et al., (1948), Amer. Heart $₹ .$, 35, 438.

GUERRA, F. (1946), Science, 103, 686.

HOLBROOK, W. P. (1944), Y.A.M.A., 126, 84.

HOLBROOK, W. P., and VAN RAVENSWAAY, A. C. (1944), Ibid., 126; 84.

JONES, T. D., and MOTE, J. R. (1948), New Eng. F. Med., 88, 325. KERR, W. J. (1948), Ann. Int. Med., 29, 587.

KLINGE, FRITZ, (1933), Ergebn. der allg. Path. U. path. Anat., 27, 1 .

KUTTNER, ANN G. (1945), f. Pediat., 26, 216.

LONG, D. A., MILES, A. A., and PERRY, W. L. M. (195 Ia), Lancet, i, 1085 .

LONG, D. A., MILES, A. A., and PERRY, W. L. M. (1951b), Ibid., 1, 1392.

MACNEAL, W. J., et al. (1945), Science M.S., ror, 415.

MACNEAL, W. J., et al. (1946), Ibid., 103, 620.

MALINER, M. M., and AMSTERDAM, S. D. (1947), f. Pediat., 3I, 658 .

MANTLE, ALFRED (1887), B.M.Y., 1, 1381 .

MASSELL, B. F., DOW, J. W., and JONES, T. D. (1948), F.A.M.A., 138, 1030 .

MENKIN, W. (1931), Э. Exper. Med., 53, 647.
MEYER, K. (1938), Symposia on Quart. Biol., 6, 91.

MEYER, K. (1947), Physiol., Rev., 27, 335.

MEYER, K. (1948), Ann. Rheumat. Dis., 7, 33.

MURPHY, G. E., and SWIFT, H. F. (1949), F. Exper. Med., $89,687$.

NEWSHOLME, ARTHUR (1895), Lancet, i, 589, 657.

PICKLES, W. N. (1943), Ibid., Ii, 24 I.

PILOT, I. (1944), Proc. Cent. Soc. Clin. Res., 17, 70.

POYNTON, F. J., and PAINE, ALEXANDER (1900), Lancet, ii, 86r, 932.

POYNTON, F. J., and PAINE, ALEXANDER (1913), ' Researches on Rheumatism,' London, Churchill.

RANTZ, L. A., et al. (1945), Arch. Int. Med., 76, 131.

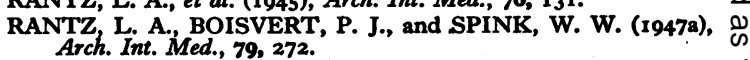

RANTZ, L. A., BOISVERT, P. J., and SPINK, W. W. (1947b), Ibid., 79, 401.

RAGAN, CHARLES (1950), editor, 'Connective Tissues,' Josiah Macy Jr. Foundation.

RICH, A. R. (1946), Harvey Lect., 42, 106.

RINEHART, J. F. (1943), Ann. Rheumat. Dis., 3, 154.

ROTHBARD, SIDNEY (1948), f. exper. Med., 88, 325.

SCHLESINGER, B., et al. (1935), Lancet, i, 1145.

SELYE, HANS (1950), B.M.F., $i, 1383$.

SHORT, et al. (1934), Am. F. Med. Sc., 187, 615.

SINGER, GUSTAV (1895), Wien. Klin. Wchnschr., 8,.449.

SWIFT, H. F. (1947), Amer. F. Med., 2, 168.

THIROLOIX (1896), Semaine med.

WILSON, MAY G., WHEELER, G. W., and LEACH, M. M O (1935), F. Clin. Invest., I4, 333.

WILSON, MAY G. (1944), Y.A.M.A., 124, 1188.

\section{RUTHIN CASTLE, NORTH WALES}

A Clinic for the diagnosis and treatment of Internal Diseases (except Mental or Infectious Diseases). The Clinic is provided with a staff of doctors, technicians and nurses.

The surroundings are beautiful. The climate is mild. There is central heating throughout. The annual rainfall is 30.5 inches, that is, less than the average for England.

The Fees are inclusive and vary according to the room occupied.

For particulars apply to THE SECRETARY, Ruthin Castle, North Wales. 